\title{
Optimal combined anteversion pattern for obtaining a wider range of motion without prosthetic impingement after total hip arthroplasty: a three- dimensional analysis study
}

Ryo Hidaka ( $\nabla$ qqdr59qd@yahoo.co.jp )

Teikyo University

Kenta Matsuda

Teikyo University

Masaki Nakamura

Toranomon Hospital

Shigeru Nakamura

Teikyo University Mizonokuchi Hospital

Hirotaka Kawano

Teikyo University

\section{Research Article}

Keywords: activities of daily living, arthroplasty, hip prosthesis, joint dislocation, polyethylene, X-ray computed tomography

Posted Date: September 8th, 2021

DOl: https://doi.org/10.21203/rs.3.rs-871792/v1

License: (c) (1) This work is licensed under a Creative Commons Attribution 4.0 International License.

Read Full License

Version of Record: A version of this preprint was published at Journal of Orthopaedic Surgery and Research on April 10th, 2022. See the published version at https://doi.org/10.1186/s13018-022-03112-6. 


\section{Abstract \\ Background}

Obtaining a larger theoretical range of motion (ROM) is crucial to avoid prosthetic impingement after total hip arthroplasty (THA); however, no reports have examined the permissible range values of combined anteversion (CA) satisfying targeted ROM without prosthetic impingement. This retrospective study aimed to evaluate the possible postoperative CA extent that would allow meeting target ROM criteria according to Yoshimine's theory using computed tomography (CT)-based three-dimensional motion analysis after THA.

\section{Methods}

This study included 114 patients (133 hips) who underwent cementless primary THA using a CT-based navigation system and implants (oscillation angle $\geq 135^{\circ}$ ). Implant positions were determined using Yoshimine's CA formula. Postoperative evaluation was conducted using a three-dimensional templating software for CT data. The postoperative Yoshimine's and Widmer's CA was calculated, and the difference between the target and postoperative values was defined as the error of Yoshimine's CA and Widmer's CA. Prosthetic ROM was assessed by Yoshimine's stringent criteria for activities of daily living. Based on fulfilling these criteria, all patients were divided into the ROM (+) and ROM (-) groups. Evaluation items were compared between the two groups.

\section{Results}

There were 111 and 22 hips in the ROM (+) and ROM (-) groups, respectively. A significant difference was noted in the absolute error of Yoshimine's and Widmer's CA between the two groups. Using receiver operating characteristic analysis, threshold values of 6.0 (higher values indicate greater disability; sensitivity $90.9 \%$, specificity $72.1 \%$ ) for the absolute Yoshimine's CA difference (area under the curve [AUC] $0.87, P<0.01$ ) and 6.9 (higher values indicate greater disability; sensitivity $68.2 \%$, specificity $88.3 \%$ ) for the absolute Widmer's CA difference (AUC $0.83, P<0.01$ ) were predictors in the ROM $(-)$ group.

\section{Conclusions}

The target range of Yoshimine's CA $\left(90.8^{\circ} \pm 6.0^{\circ}\right)$ and Widmer's CA values $\left(37.3^{\circ} \pm 6.9^{\circ}\right)$ was crucial in implant orientation for obtaining theoretical ROM without prosthetic impingement after THA.

\section{Background}

Impingement between the cup and femoral neck causes dislocation, pain, polyethylene liner wear, and component loosening after total hip arthroplasty (THA). The optimum orientation of implants is 
important to obtain a wider range of motion (ROM) and to avoid impingement between prosthetic components. Combined anteversion (CA) is one of the indexes widely used in cup-stem orientations. CA, the sum of the cup and stem anteversion, has been recommended to be between $25^{\circ}$ and $35^{\circ}$ in men and up to $45^{\circ}$ in women [1]. The dislocation risk was reportedly 6.9 times greater if CA fell outside the range of $40^{\circ}-60^{\circ}$ after THA [2]. Another report recommended that CA should be within $40^{\circ}-60^{\circ}$ to reduce dislocations after THA using the CA technique [3]. Therefore, the generally accepted CA has been reported to range from $40^{\circ}$ to $60^{\circ}$. There have been few reports on the target CA value for establishing the criteria for ROM without prosthetic impingement based on activities of daily living analyzed by three-dimensional simulation and mathematical formulas $[4,5]$. Widmer et al. [4] reported the following formula for the target CA value using a three-dimensional computer model:

cup radiographic anteversion $+0.7 \times$ stem anteversion $=37.3^{\circ}$.

This was obtained when the cup radiographic inclination was between $40^{\circ}$ and $45^{\circ}$ according to the following six ROM conditions: flexion $\geq 130^{\circ}$, internal rotation $\geq 80^{\circ}$, extension $\geq 40^{\circ}$, external rotation $\geq$ $40^{\circ}$, abduction $\geq 50^{\circ}$, and adduction $\geq 50^{\circ}$. Yoshimine et al. [5] reported a similar analytical approach to these mathematical formulas and indicated four ROM conditions of flexion $>120^{\circ}$, internal rotation at $90^{\circ}$ flexion $>45^{\circ}$, extension $>30^{\circ}$, and external rotation $>40^{\circ}$. In addition, their study showed that the CA value to fulfill their criteria could be determined using the formula: cup radiographic inclination + cup anatomical anteversion $+0.8 \times$ stem anteversion $=90.8^{\circ}$. These were simulation studies. However, in clinical practice, postoperative implant positions often could not be accurately reproduced according to preoperative planning. The use of navigation systems has improved the implant placement accuracy, making it possible to place implants closer to the target CA with less error [6, 7]. However, to the best of our knowledge, no study to date has reported the degree of error that is allowed from the target CA value to apply these CA theories to THA to meet the ROM criteria.

Therefore, the purpose of our study was to evaluate the extent to which postoperative CA could be allowed to meet the target ROM criteria according to Yoshimine's CA theory using computed tomography (CT)-based three-dimensional motion analysis after THA.

\section{Methods}

This retrospective case-series study was approved by the Institutional Review Board (approval number: 21-086). This study included patients who underwent primary THA using a CT-based navigation system (Stryker CT-Hip System V1.1, Stryker-Leibinger GmbH \& Co. KG, Freiberg, Germany) at our institution between September 2014 and December 2020. Inclusion criteria were the use of two types of components: (1); G7 cup and Taperloc complete stem (Zimmer Biomet Holdings, Inc., Warsaw, IN, USA), (2); SQRUM cup, and J-Taper stem (Kyocera, Inc., Osaka, Japan), and the head size more than $32 \mathrm{~mm}$. These components had an oscillation angle of $>135^{\circ}$ according to Yoshimine's CA theory. Exclusion criterion was pelvic deformity that could not set the pelvic coordinate system. 


\section{Preoperative planning}

A preoperative CT scan extending from the iliac wing to the knee joint was obtained using a helical CT scanner (Light-Speed VCT; GE Medical Systems, Milwaukee, WI, USA). All imaging data were transferred to a CT-based three-dimensional templating system for preoperative planning (ZedHip ${ }^{\text {TM }}$ Lexi Co., Ltd., Tokyo, Japan). The pelvic coordinate system was the anterior pelvic plane, which was defined by the anterior superior iliac spine and the pubic tubercle. The femoral coordinate system was defined by the posterior condylar plane of the femur, which was formed by the proximal posterior surface, lateral condyle, and medial condyle. The size and anteversion of the stem were adjusted to match the shape of the proximal femoral medullary canal. Stem anteversion was defined as the angle formed between the proximal femoral stem axis and the line tangential to the bilateral posterior femoral condylar margin on the axial plane. A modular stem was selected for the hips with an anticipated stem anteversion of $<10^{\circ}$ or $>40^{\circ}$ in preoperative planning. Non-modular stems were used in all the enrolled hips in anticipation of stem anteversion in the range of $10^{\circ}-40^{\circ}$. The target cup radiographic inclination was determined to be $43^{\circ}$ in all the hips. Cup anteversion was calculated for each hip using the following formula: cup radiographic inclination + cup anatomical anteversion + stem anteversion $\times 0.8=90.8^{\circ}$. The planning data were entered into the CT-based navigation system.

\section{Surgical procedure}

All surgeries were performed using a posterolateral approach with the patient in the lateral decubitus position. A pelvic tracker was fixed percutaneously on the ipsilateral ilium using two 4-mm pins and an external fixation device (Hoffman II, Stryker-Leibinger GmbH \& Co. KG, Freiberg, Germany). In addition, surface matching of the pelvis was completed by digitizing more than 30 points around the acetabulum. The acetabular cup was implanted using a navigation system, and the stem was manually placed according to the anatomy of the proximal femur. All surgeries were performed by either of the two senior authors.

\section{Postoperative evaluation}

CT was performed 1-2 weeks postoperatively using a minimal radiation dose protocol [8]. Postoperative CT data were transferred to ZedHip for three-dimensional analysis. All preoperative planning and postoperative CT reference points were matched manually, and implant orientation was measured. This software was capable of simulating and detecting implant impingement, which allowed the maximum prosthetic ROM to be defined as the number of degrees of movement before the occurrence of implant impingement.

\section{Measurements}

Postoperative Yoshimine's CA and Widmer's CA were calculated from the implant orientation measurements. The difference between the target CA value $\left(90.8^{\circ}\right)$ and the postoperative Yoshimine's CA was defined as the error of Yoshimine's CA. The difference between the target CA value $\left(37.3^{\circ}\right)$ and the postoperative Widmer's CA was defined as the error of Widmer's CA. The difference between preoperative 
and postoperative values in each CA component, cup radiographic inclination, cup anatomic anteversion, and stem anteversion was also calculated. In ROM-simulation analysis, the neutral hip position of our system was defined as the position in which all corresponding axes in the pelvic and femoral coordinate systems were parallel. Moreover, the prosthetic ROM in those directions was measured using a previously reported method [9]. Several reports have shown that the ROM was affected by the femoral offset and head diameter [10-13]; therefore, in all cases, the femoral offset was standardized to a stem with a standard offset type and the minimum neck length for each stem. The femoral head diameter was standardized to $32 \mathrm{~mm}$, and the prosthetic ROM was measured.

The offset of the Taperloc complete stem (neck shaft angle $133^{\circ}$, cone 12/14 taper) and J-Taper stem (neck shaft angle $130^{\circ}$, cone $9 / 10$ taper) increases with stem size and ranges from 31.2 to $37.7 \mathrm{~mm}$ and 32 to $40 \mathrm{~mm}$, respectively, for the standard offset geometry.

We investigated whether all directions were fulfilled based on Yoshimine's stringent ROM conditions for activities of daily living (flexion $>120^{\circ}$, internal rotation $>45^{\circ}$ at flexion of $90^{\circ}$, external rotation $>40^{\circ}$ at flexion $0^{\circ}$, and extension $>30^{\circ}$ ). Patients who fulfilled all criteria were classified into the ROM (+) group and patients who did not fulfill the criteria were classified into the ROM (-) group.

\section{Statistical analysis}

Demographic variables are presented as mean, standard deviation, and range for continuous data. Fisher's exact test was used to compare categorical parameters, and the Wilcoxon rank-sum test was used to compare continuous parameters between the groups. Univariate analysis was conducted on each possible factor to screen for significant factors related to the ROM (-) group. Optimal threshold scores for the absolute error of Yoshimine's CA and Widmer's CA that predicted the ROM (-) group were calculated using a nonparametric receiver operating characteristic (ROC) analysis. Youden's index was used to calculate the optimal threshold scores to obtain the best balance of sensitivity and specificity [14]. The significant risk factors identified by univariate analysis were examined by logistic regression analysis to determine their contribution to the ROM (-) group. We defined statistical significance at $5 \%(P<0.05)$ level. Statistical analyses were performed using SPSS 24.0 software (IBM Corp., Armonk, NY, USA).

\section{Results}

The patients' demographics and implant size are summarized in Table 1. We reviewed data from 133 hips (114 patients) in this study. There were 111 hips in the ROM (+) group and 22 hips in the ROM (-) group. The following details were noted for the ROM (-) group: 1 hip $\left(120^{\circ}\right)$ in flexion, 6 hips (range, $33^{\circ}-$ $45^{\circ}$ ) in internal rotation at flexion of $90^{\circ}, 9$ hips (range, $30^{\circ}-40^{\circ}$ ) in external rotation, 2 hips (range, $27^{\circ}-$ $29^{\circ}$ ) in extension, 1 hip $\left(115^{\circ}\right.$ and $\left.45^{\circ}\right)$ in flexion and internal rotation at flexion of $90^{\circ}$, and 3 hips (range, $28^{\circ}-36^{\circ}$ and $26^{\circ}-29^{\circ}$ ) in external rotation and extension. Univariate analysis indicated that there was a significant difference in age, sex, and absolute error of Yoshimine's CA and Widmer's CA between the two groups (Table 2); however, there was no significant difference in Yoshimine's CA and Widmer's CA. In ROC analysis, a threshold value of 6.0 (higher values indicate greater disability; sensitivity $90.9 \%$, specificity 
72.1\%) for the absolute error of Yoshimine's CA was predictive of the ROM (-) group (AUC $0.87, P<0.01$ ) (Fig. 1), and a threshold value of 6.9 (higher values indicate greater disability; sensitivity $68.2 \%$, specificity $88.3 \%$ ) for the absolute error of Widmer's CA was predictive of the ROM (-) group (AUC 0.83, $P<0.01$ ) (Fig. 2). Multivariate analysis demonstrated that the absolute error of Yoshimine's CA was significantly associated with fulfilling the ROM criteria (Table 3).

Table 1

Patient demographics

\begin{tabular}{|c|c|c|}
\hline \multicolumn{2}{|l|}{ Demographics } & Values \\
\hline \multicolumn{2}{|c|}{ Number of patients (hips/patients) } & $133 / 114$ \\
\hline \multicolumn{2}{|c|}{ Sex (male/female) } & $32 / 82$ patients \\
\hline \multicolumn{2}{|l|}{ Age (years) ${ }^{a}$} & $64 \pm 11(39-84)$ \\
\hline \multicolumn{2}{|l|}{$\mathrm{BMI}\left(\mathrm{kg} / \mathrm{m}^{2}\right)^{\mathrm{a}}$} & $24 \pm 4(16-40)$ \\
\hline \multirow[t]{4}{*}{ Diagnosis (hips) } & Osteoarthritis & 102 \\
\hline & Osteonecrosis of the femoral head & 24 \\
\hline & Femoral neck fractures & 5 \\
\hline & Rheumatoid arthritis & 1 \\
\hline \multicolumn{2}{|l|}{ Cup size } & $50(46-62)$ \\
\hline \multirow[t]{2}{*}{ Stem size } & Taperloc stem & $9(4-17)$ \\
\hline & J-Taper stem & $6(1-11)$ \\
\hline \multicolumn{3}{|c|}{ a Values are given as mean \pm standard deviation (SD) (range) } \\
\hline \multicolumn{3}{|c|}{ BMI, body mass index } \\
\hline
\end{tabular}


Table 2

Univariate analysis of the factors for each range-of-motion [ROM (+) and ROM (-)] group

\begin{tabular}{|c|c|c|c|c|c|}
\hline \multirow{2}{*}{\multicolumn{2}{|c|}{ Factors }} & \multirow{2}{*}{$\begin{array}{l}\text { Total } \\
\mathrm{N}=133\end{array}$} & \multirow{2}{*}{$\begin{array}{l}\text { ROM (+) } \\
\mathrm{N}=111\end{array}$} & \multirow{2}{*}{$\begin{array}{l}\text { ROM (-) } \\
\text { N }=22\end{array}$} & \multirow[t]{2}{*}{$P$ values } \\
\hline & & & & & \\
\hline Age (years) ${ }^{a}$ & & & $63.4 \pm 11.0$ & $59.2 \pm 9.2$ & 0.03 \\
\hline \multirow[t]{2}{*}{ Sex (hips) } & Male & 41 & 29 & 12 & 0.01 \\
\hline & Female & 92 & 82 & 10 & \\
\hline \multicolumn{2}{|l|}{ BMI $\left(\mathrm{kg} / \mathrm{m}^{2}\right)^{\mathrm{a}}$} & & $24.4 \pm 4.2$ & $23.8 \pm 3.7$ & 0.71 \\
\hline \multirow[t]{4}{*}{ Diagnosis (hips) } & $\mathrm{OA}$ & 101 & 88 & 15 & 0.12 \\
\hline & ONFH & 24 & 18 & 6 & \\
\hline & FNF & 5 & 5 & 0 & \\
\hline & RA & 1 & 0 & 1 & \\
\hline \multirow[t]{2}{*}{ Implants (hips) } & G7-Taperloc & 80 & 68 & 12 & 0.63 \\
\hline & SQRUM-J-taper & 53 & 43 & 10 & \\
\hline \multicolumn{2}{|c|}{ Yoshimine`s CA (degrees) a } & $91.1 \pm 7.4$ & $90.5 \pm 5.6$ & $93.6 \pm 13.1$ & 0.06 \\
\hline \multicolumn{2}{|c|}{ Widmer`s CA (degrees) ${ }^{a}$} & $38.0 \pm 5.6$ & $37.6 \pm 4.3$ & $40.2 \pm 9.8$ & 0.06 \\
\hline \multicolumn{2}{|c|}{ Absolute error of Yoshimine`s CA (degrees) ${ }^{a}$} & $5.7 \pm 4.6$ & $4.5 \pm 3.2$ & $11.9 \pm 5.5$ & $<0.01$ \\
\hline \multicolumn{2}{|c|}{ Absolute error of Widmer`s CA (degrees) ${ }^{a}$} & $4.4 \pm 3.6$ & $3.5 \pm 2.5$ & $8.8 \pm 4.8$ & $<0.01$ \\
\hline \multicolumn{6}{|c|}{ Each factors of CA } \\
\hline \multicolumn{2}{|c|}{ Stem anteversion (degrees) ${ }^{a}$} & $5.4 \pm 4.4$ & $5.1 \pm 4.0$ & $6.9 \pm 5.5$ & 0.18 \\
\hline \multicolumn{2}{|c|}{ Cup radiographic inclination (degrees) ${ }^{a}$} & $3.1 \pm 2.3$ & $3.0 \pm 2.3$ & $3.7 \pm 2.4$ & 0.17 \\
\hline \multicolumn{2}{|c|}{ Cup anatomical anteversion (degrees) ${ }^{a}$} & $4.3 \pm 3.6$ & $3.9 \pm 3.1$ & $6.0 \pm 5.3$ & 0.08 \\
\hline \multicolumn{6}{|c|}{ a Values are given as mean \pm standard deviation (SD) (range) } \\
\hline
\end{tabular}


Table 3

Multivariate analysis of the factors for the range-of-motion $(-)$ group

\begin{tabular}{|llll|}
\hline Factors & Odds ratio & $95 \%$ confidence interval & $P$ value \\
\hline Age & 0.97 & $0.91-1.03$ & 0.26 \\
\hline Sex & 0.34 & $0.09-1.31$ & 0.12 \\
\hline BMI & 0.90 & $0.76-1.07$ & 0.23 \\
\hline Absolute error of Yoshimine`s CA & 1.47 & $1.25-1.71$ & $<0.01$ \\
\hline BMI, body mass index; CA, combined anteversion. & \\
\hline
\end{tabular}

\section{Discussion}

CA is widely used as an index of implant orientation. To the best of our knowledge, no study to date has examined the permissible range of CA values to satisfy the ROM criteria for activities of daily living without prosthetic impingement with CA after THA. This study demonstrated that the range of postoperative Yoshimine's CA and Widmer's CA satisfied the ROM conditions for activities of daily living after THA.

Few studies have evaluated ROM on simulation after THA clinically, as in this study. One study has shown impingement-free ROM after THA with the stem-first technique using imageless navigation [15]. Their ROM criteria to be satisfied were defined as: flexion $>110^{\circ}$, internal rotation at a flexion $90^{\circ}>30^{\circ}$, extension $>30^{\circ}$, abduction $>45^{\circ}$, abduction $>50^{\circ}$, and adduction $>30^{\circ}$. Out of the 57 cases using imageless navigation, $48(84 \%)$ met all the ROM criteria. The ROM criteria were different from the strict criteria in our study, except for external rotation. However, $83.5 \%$ (111/133 hips) of the cases in our study met our ROM criteria. This report has not evaluated implant orientation before or after surgery and the target $\mathrm{CA}$ and did not indicate the range of postoperative CA to meet the ROM criteria. We evaluated the impingement-free ROM by postoperative $\mathrm{CT}$ after THA with a cup-first technique using CT-based navigation targeted by Yoshimine's CA, according to a previous study [16]. We reported that $45(88 \%)$ of the 51 hips met all the Yoshimine's ROM criteria. Moreover, postoperative Yoshimine's CA within the target range of $90.8 \pm 10$ would significantly meet all ROM criteria. However, we have not examined whether postoperative Yoshimine's CA within $10^{\circ}$ from the target value would be suitable as a range to meet the Yoshimine's ROM criteria.

Yoshimine's CA and Widmer's CA theories recommended a target CA value of 90.8 and 37.3. Given that navigation systems have potential to implant components in an optimal orientation, there have been many reports on the accuracy of implant orientation in THA using these navigation systems. Inaba et al. [7] reported absolute differences between preoperative and postoperative cup inclination as $3.2^{\circ} \pm 2.3^{\circ}$, cup anteversion $4.0^{\circ} \pm 3.5^{\circ}$, stem anteversion $3.9^{\circ} \pm 5.0^{\circ}$, and Widmer's CA $5.3^{\circ} \pm 5.2^{\circ}$ using a CT-based navigation system. Dorr et al. [17] showed that the average CA was $37.6^{\circ} \pm 7.0^{\circ}$, and 45 cases $(96 \%)$ out of 47 were within the target $\mathrm{CA}$ of $25^{\circ}-50^{\circ}$ using an imageless navigation system. Although tools such as 
navigation systems were used for accurate implant orientation, errors may occur between preoperative and postoperative implant orientation. It has been difficult to place components to set target CA accurately during THA. Therefore, we consider that it is important to examine the range of postoperative CA obtaining the target ROM criteria to be indexes evaluated for implant orientation after surgery and to set an implant position intraoperatively. This study revealed that the absolute value of difference between the target and postoperative values of Yoshimine's CA was a significant factor in whether or not the ROM criteria were met using univariate and multivariate analyses. This study showed that postoperative Yoshimine's CA and Widmer's CA should be within $90.8^{\circ} \pm 6.0^{\circ}$ and $37.3^{\circ} \pm 6.9^{\circ}$, which is likely to meet the Yoshimine's ROM criteria for activities of daily living. Our results indicated a useful target range of Yoshimine's CA and Widmer's CA in considering the error related to implant orientation in THA.

The absolute error of Yoshimine's CA and Widmer's CA was $5.7 \pm 4.6$ and $4.4 \pm 3.6$, respectively, in our study, which is comparable to Widmer's CA $5.3^{\circ} \pm 5.2^{\circ}$ of previous studies using CT-based navigation [7]. The use of CT-based navigation could predict whether the postoperative CA will place the implant within the target range of $\mathrm{CA}$.

There were two cases in which the prosthetic ROM did not meet the Yoshimine's ROM criteria, even though the Yoshimine's CA was in the range of $90.8^{\circ} \pm 6.0^{\circ}$. The Yoshimine's CA in two cases was $88.5^{\circ}$ and $92.6^{\circ}$. These cases did not reach the ROM boundary only for one direction each of internal rotation at flexion $90^{\circ}$ and external rotation. These cases did not reach the ROM benchmark due to a difference of $1^{\circ}$. Three-dimensional templating software has been shown to have excellent interobserver and intraobserver reliability for component alignment in THA [18]. Inoue et al. [19] reported that error measurement might be performed using this software when manually matching the reference points between the preoperative plan and postoperative evaluation on CT. Two studies have reported that the sagittal alignment of the stem had an influence on impingement-free ROM [20,21]. Therefore, it was considered that a measurement error with the three-dimensional templating software occurred, which influenced the sagittal alignment of the stem.

This study has several limitations. First, we excluded the cases wherein the stem anteversion was $>40^{\circ}$ or $<10^{\circ}$. For cases wherein the stem anteversion was $>40^{\circ}$, cup radiographic anteversion was set to $<10^{\circ}$, according to the CA theory, and if errors occurred in these cases, cup radiographic anteversion may have led to retroversion. Widmer et al. [4] did not recommend cup radiographic anteversion of $<10^{\circ}$ to be incompatible with the intended ROM. When stem anteversion was $<10^{\circ}$, cup radiographic anteversion was $>30^{\circ}$ and the acetabulum could not sufficiently cover the posterior area of the cup. A cementless stem was implanted manually without the use of navigation systems in this study. Anteversion of the cementless stem was hard to control because of the anatomy of the proximal femur. A broad range of postoperative stem anteversion has been reported in the literature [22-24]. The postoperative error may cause the stem anteversion to become retroverted. Dorr et al. [17] reported similar results showing that 2 of 47 hips exhibited postoperative $\mathrm{CA}$ of $<25^{\circ}$ due to the retroverted native femoral anteversion that was not in the safe zone. Therefore, stem anteversion should be avoided. 
Second, two types of implant designs and oscillation angles were included. The formula of Yoshimine's CA was calculated based on the assumption that the implant design had an oscillation angle of $135^{\circ}$ [5]. The study showed that the safe zone for an oscillation angle of $120^{\circ}$ was extremely small, and implant designs with a greater oscillation angle were recommended. Two implant designs had an oscillation angle of $\geq 135^{\circ}$ in our study. Many varieties of implant designs have been used widely in THA. Our study showed that the use of two types of implants with an oscillation angle of $\geq 135^{\circ}$ could fulfill the Yoshimine's ROM criteria within the range of $\pm 6.0^{\circ}$ according to Yoshimine's CA. However, this study may not be accurate when using implants with an oscillation angle of $\leq 135^{\circ}$. Third, this simulation study investigated only ROM without prosthetic impingement. Clinically, ROM without bone and soft-tissue impingements was also a risk factor of dislocation. However, we did not evaluate them. The factors that the surgeon could control to avoid dislocation were to place the optimum implant positions and to increase prosthetic ROM.

\section{Conclusions}

It is ideal to place implants according to CA closer to the target value for meeting the ROM criteria according to CA theory. However, the target and postoperative CA values can be different due to an error in implant placement during surgery. In this study, if postoperative Yoshimine's CA and Widmer's CA were within $6.0^{\circ}$ and $6.9^{\circ}$, respectively, from the target CA value after THA, the potential ROM without implant impingement could meet Yoshimine's ROM criteria for activities of daily living. This range of CA values could serve as an index for postoperative implant orientations. This may reduce problems caused by implant impingement, such as dislocation.

\section{Abbreviations}

THA: Total hip arthroplasty; ROM: Range of motion; CA: Combined anteversion; CT: Computed tomography; ROC: Receiver operating characteristic

\section{Declarations}

\section{Ethics approval and consent to participate}

This study was performed in line with the principles of the Declaration of Helsinki (1964) and its subsequent amendments and was approved by the institutional review board of Teikyo University (IRB approval No. 21-086). Informed consent was obtained from all individual participants included in the study.

\section{Consent for publication}

All individuals have given general consent in the use of their data, including imaging, for analysis and publication. 
Availability of data and materials

The datasets used and analyzed during the current study are available from the corresponding author on reasonable request.

\section{Competing interests}

The authors declare that they have no competing interests

\section{Funding}

This study received no funding.

\section{Author contributions}

All authors contributed to the study conception and design. Material preparation, data collection and analysis were performed by $\mathrm{RH}$ and $\mathrm{KM}$. The first draft of the manuscript was written by $\mathrm{RH}$ and all authors commented on previous versions of the manuscript. All authors read and approved the final manuscript.

\section{Acknowledgments}

We would like to thank Dr. Takao Fukagawa, Kiyoko Uno, and Tetsuji Kaneko at Teikyo Academic Research Center for their assistance with the study methods and statistical methods. We would like to thank Editage (www.editage.com) for English language editing.

\section{References}

1. Ranawat CS, MaynardMJ. Modern technique of cemented total hip arthroplasty. Techniques in Orthopaedics. 1991;6(3):17-25. https://doi.org/10.1097/00013611-199109000-00004.

2. Jolles BM, Zangger P, Leyvraz PF. Factors predisposing to dislocation after primary total hip arthroplasty: a multivariate analysis. J Arthroplast. 2002;17(3):282-8. https://doi.org/10.1054/arth.2002.30286.

3. Nakashima Y, Hirata M, Akiyama M, Itokawa T, Yamamoto T, Motomura G, Ohishi M, Hamai S, Iwamoto Y. Combined anteversion technique reduced the dislocation in cementless total hip arthroplasty. Int Orthop. 2014;38(1):27-32. https://doi.org/10.1007/s00264-013-2091-2

4. Widmer KH, Zurfluh B. Compliant positioning of total hip components for optimal range of motion. J Orthop Res. 2004;22(4):815-821. https://doi.org/10.1016/j.orthres.2003.11.001

5. Yoshimine $F$. The safe-zones for combined cup and neck anteversions that fulfill the essential range of motion and their optimum combination in total hip replacements. J Biomech. 2006;39(7):13151323. https://doi.org/10.1016/j.jbiomech.2005.03.008 
6. Kitada M, Nakamura N, Iwana D, Kakimoto A, Nishii T, Sugano N. Evaluation of the accuracy of computed tomography-based navigation for femoral stem orientation and leg length discrepancy. $J$ Arthroplast. 2011;26(5):674-679. https://doi.org/10.1016/j.arth.2010.08.001

7. Inaba Y, Kobayashi N, Suzuki H, Ike H, Kubota S, Saito T. Preoperative planning for implant placement with consideration of pelvic tilt in total hip arthroplasty: postoperative efficacy evaluation. BMC Musculoskelet Disord. 2016;17:280. https://doi.org/10.1186/s12891-016-1120-x

8. Arai N, Nakamura S, Matsushita T, Suzuki S. Minimal radiation dose computed tomography for measurement of cup orientation in total hip arthroplasty. J Arthroplast. 2010;25(2):263-267. https://doi.org/10.1016/j.arth.2009.01.020

9. Ohmori T, Kabata T, Kajino Y, Taga T, Hasegawa K, Inoue D, Yamamoto T, Takagi T, Yoshitani J, Ueno $\mathrm{T}$, Tsuchiya $\mathrm{H}$. Differences in range of motion with the same combined anteversion after total hip arthroplasty. Int Orthop. 2018;42(5):1021-1028. https://doi.org/10.1007/s00264-017-3653-5

10. Crowninshield RD, Maloney WJ, Wentz DH, Humphrey SM, Blanchard CR. Biomechanics of large femoral heads: what they do and don't do. Clin Orthop Relat Res. 2004;429:102-107. https://doi.org/10.1097/01.blo.0000150117.42360.f9.

11. Higashi T, Kaku N, Noda S, Tabata T, Tagomori H, Tsumura H. Effects of ball head diameter and stem neck shape in range of motion after total hip arthroplasty: a simulation study. J Orthop. 2020;18:104-109. https://doi.org/10.1016/j.jor.2019.09.015

12. Matsushita A, Nakashima Y, Jingushi S, Yamamoto T, Kuraoka A, Iwamoto Y. Effects of the femoral offset and the head size on the safe range of motion in total hip arthroplasty. J Arthroplast. 2009;24(4):646-651. https://doi.org/10.1016/j.arth.2008.02.008

13. Weber M, Merle C, Nawabi DH, Dendorfer S, Grifka J, Renkawitz T. Inaccurate offset restoration in total hip arthroplasty results in reduced range of motion. Sci Rep. 2020;10:13208. https://doi.org/10.1038/s41598-020-70059-1

14. Youden WJ. Index for rating diagnostic tests. Cancer. 1950;3(1):32-35. https://doi.org/10.1002/1097-0142(1950)3:1<32::AID-CNCR2820030106>3.0.C0;2-3

15. Renkawitz T, Weber M, Springorum HR, Sendtner E, Woerner M, Ulm K, Weber T, Grifka J. Impingement-free range of movement, acetabular component cover and early clinical results comparing 'femur-first' navigation and 'conventional' minimally invasive total hip arthroplasty: a randomised controlled trial. Bone Joint J. 2015;97-B(7):890-898. https://doi.org/10.1302/0301620X.97B7.34729

16. Nakamura S, Hidaka R, Nakamura M, Kanezaki S, Nishino H, Tamayama M. Impingement-free Range of Motion After Total Hip Arthoplasty with A Cup-First Technique Using a CT Navigation System. J Orthopaed Res Ther. 2017;5

17. Dorr LD, Malik A, Dastane M, Wan Z. Combined anteversion technique for total hip arthroplasty. Clin Orthop Relat Res. 2009;467(1):119-27. https://doi.org/10.1007/s11999-008-0598-4.

18. Wako Y, Nakamura J, Miura M, Kawarai Y, Sugano M, Nawata K. Interobserver and intraobserver reliability of three-dimensional preoperative planning software in total hip arthroplasty. $\mathrm{J}$ Arthroplast. 
2018;33(2):601-7. https://doi.org/10.1016/j.arth.2017.08.031.

19. Inoue D, Kabata T, Maeda T, Kajino Y, Fujita K, Hasegawa K, Yamamoto T, Tsuchiya H. Value of computed tomography-based three-dimensional surgical preoperative planning software in total hip arthroplasty with developmental dysplasia of the hip. J Orthop Sci. 2015;20(2):340-6. https://doi.org/10.1007/s00776-014-0683-3.

20. Renkawitz T, Haimerl M, Dohmen L, Gneiting S, Lechler P, Woerner M, Springorum HR, Weber M, Sussmann P, Sendtner E, Grifka J. The association between Femoral Tilt and impingement-free range-of-motion in total hip arthroplasty. BMC Musculoskelet Disord. 2012;13:65. https://doi.org/10.1186/1471-2474-13-65.

21. Müller M, Duda G, Perka C, Tohtz S. The sagittal stem alignment and the stem version clearly influence the impingement-free range of motion in total hip arthroplasty: a computer model-based analysis. Int Orthop. 2016;40(3):473-80. https://doi.org/10.1007/s00264-015-2845-0.

22. Fujishiro T, Hayashi S, Kanzaki N, Hashimoto S, Kurosaka M, Kanno T, Masuda T. Computed tomographic measurement of acetabular and femoral component version in total hip arthroplasty. Int Orthop. 2014;38(5):941-6. https://doi.org/10.1007/s00264-013-2264-z.

23. Sendtner E, Tibor S, Winkler R, Wörner M, Grifka J, Renkawitz T. Stem torsion in total hip replacement. Acta Orthop. 2010;81(5):579-82. https://doi.org/10.3109/17453674.2010.524596.

24. Wines AP, McNicol D. Computed tomography measurement of the accuracy of component version in total hip arthroplasty. J Arthroplast. 2006;21(5):696-701. https://doi.org/10.1016/j.arth.2005.11.008.

\section{Figures}




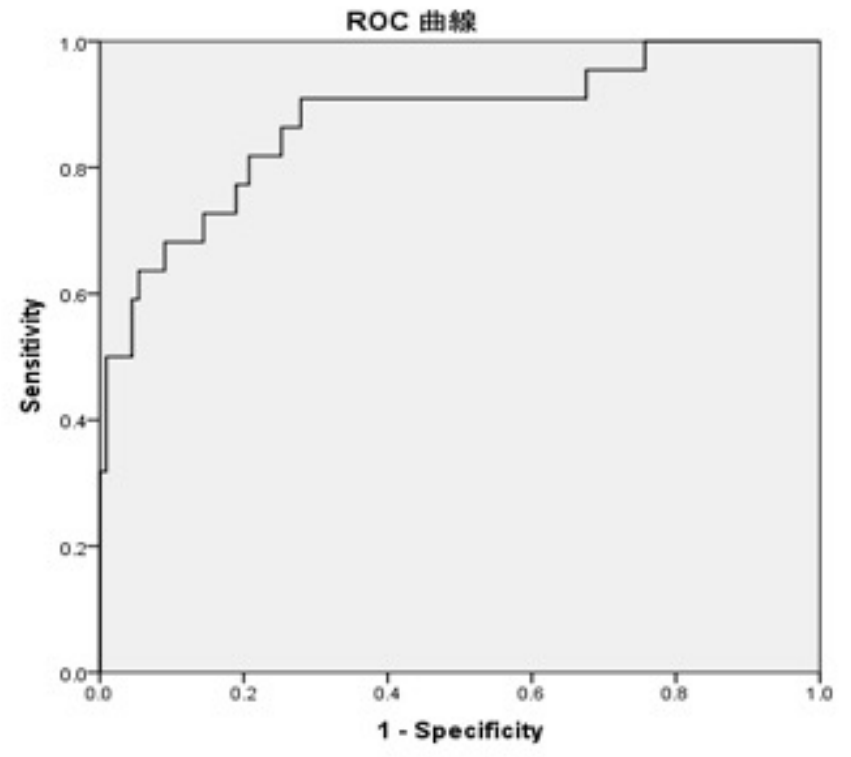

\section{Area under the Curve}

Test Result Variable: Absolute error of Yoshimine's CA

Asymptotic $95 \%$ Confidence Interval

Area Std. Error a Asymptotic Sig. ${ }^{b}$ Lower Bound Upper Bound

$\begin{array}{lllll}.874 & .046 & .000 & .784 & .964\end{array}$

a. Under the nonparametric assumption 964

b. Null hypothesis: true area $=0.5$

Coordinates for ROC curve

\begin{tabular}{ccc}
\hline Cut off value & Sensitivity (\%) N=22 & Specificity (\%) N=111 \\
\hline 5.0 & 90.9 & 62.2 \\
7.5 & 72.7 & 82.9 \\
10.0 & 63.6 & 94.6 \\
12.5 & 50.0 & 99.1 \\
15.0 & 40.9 & 99.1 \\
\hline
\end{tabular}

\section{Figure 1}

ROC curve on the predictive value of absolute error of Yoshimine's CA in the ROM (-) group ROC, receiver operating characteristic; $\mathrm{CA}$, combined anteversion 


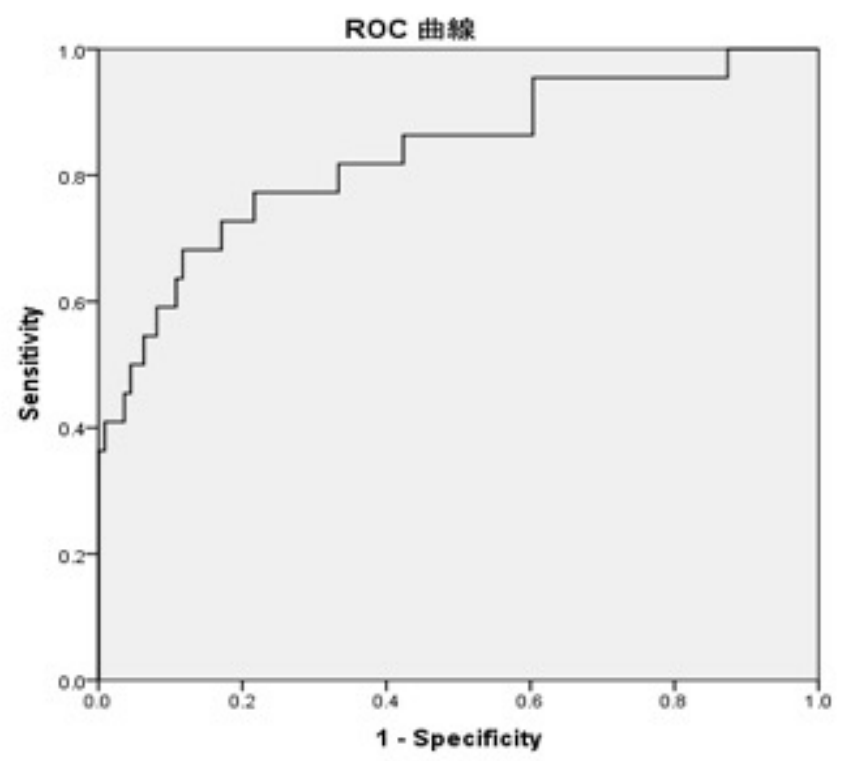

Area under the Curve

Test Result Variable: $\quad$ Absolute error of Widmer's CA

Asymptotic $95 \%$ Confidence Interval

Area Std. Error a Asymptotic Sig. ${ }^{\text {b }}$ Lower Bound Upper Bound

$\begin{array}{lllll}.833 & .054 & .000 & .727 & 938\end{array}$

a. Under the nonparametric assumption

b. Null hypothesis: true area $=0.5$

\section{Coordinates for ROC curve}

\begin{tabular}{ccc}
\hline Cut off value & Sensitivity (\%) N=22 & Specificity (\%) N=111 \\
\hline 5.0 & 77.3 & 83.9 \\
7.5 & 54.6 & 92.8 \\
10.0 & 40.9 & 97.3 \\
12.5 & 31.8 & 100.0 \\
15.0 & 18.2 & 100.0 \\
\hline
\end{tabular}

\section{Figure 2}

ROC curve on the predictive value of absolute error of Widmer's CA in the ROM (-) group ROC, receiver operating characteristic; $\mathrm{CA}$, combined anteversion 